\title{
Stabilized homoserine o-succinyltransferases (MetA) or L-methionine partially recovers the growth defect in Escherichia coli lacking ATP-dependent proteases or the DnaK chaperone
}

Elena A Mordukhova, Dooil Kim and Jae-Gu Pan ${ }^{*}$

\begin{abstract}
Background: The growth of Escherichia coli at elevated temperatures is limited due to the inherent instability of homoserine o-succinyltransferase, MetA, which is the first enzyme in the methionine biosynthesis pathway. MetA is also unstable under other stressful conditions, such as weak organic acids and oxidative stress. The MetA protein unfolds, even at $25^{\circ} \mathrm{C}$, forms considerable aggregates at $37^{\circ} \mathrm{C}$ and completely aggregates at $44^{\circ} \mathrm{C}$.

Results: We extended the MetA mutation studies using a consensus concept based on statistics and sequence database analysis to predict the point mutations resulting in increased MetA stability. In this study, four single amino acid substitutions (Q96K, 1124L, I229Y and F247Y) in MetA designed according to the consensus concept and using the I-mutant2.0 modeling tool conferred accelerated growth on the E. coli strain WE at $44^{\circ} \mathrm{C}$. MetA mutants that enabled $E$. coli growth at higher temperatures did not display increased melting temperatures $\left(T_{m}\right)$ or enhanced catalytic activity but did show improved in vivo stability at mild $\left(37^{\circ} \mathrm{C}\right)$ and elevated $\left(44^{\circ} \mathrm{C}\right)$ temperatures. Notably, we observed that the stabilized MetA mutants partially recovered the growth defects of $E$. coli mutants in which ATP-dependent proteases or the DnaK chaperone was deleted. These results suggest that the impaired growth of these E. coli mutants primarily reflect the inherent instability of MetA and, thus, the methionine supply. As further evidence, the addition of methionine recovered most of the growth defects in mutants lacking either ATP-dependent proteases or the DnaK chaperone.
\end{abstract}

Conclusions: A collection of stable single-residue mutated MetA enzymes were constructed and investigated as background for engineering the stabilized mutants. In summary, the mutations in a single gene, metA, reframe the window of growth temperature in both normal and mutant E. coli strains.

Keywords: Escherichia coli, Thermostability, Homoserine o-succinyltransferase (MetA), Growth rate, ATP-dependent proteases, DnaK chaperone

\section{Background}

Methionine is an essential amino acid in mammalian cells, although most bacteria, fungi and plants synthesize this amino acid de novo from aspartate [1]. Methionine participates in protein biosynthesis both as an initial amino acid and as one of the basic building blocks [2]. In Escherichia coli, the first enzyme in the methionine

\footnotetext{
* Correspondence: jgpan@kribb.re.kr

Superbacteria Research Center, Korea Research Institute of Bioscience and Biotechnology (KRIBB), 111 Gwahangno, Yuseong-gu, Daejeon 305-806, South Korea

biosynthesis pathway, homoserine $o$-succinyltransferase (MetA) [1,3-5], is extremely sensitive to many stress conditions (e.g., thermal, oxidative or acidic stress) [6-8]. At temperatures higher than $25^{\circ} \mathrm{C}$, MetA activity is reduced, and the protein tends to unfold, resulting in a methionine limitation in E. coli growth [9]. MetA reversibly unfolds at temperatures approaching $42^{\circ} \mathrm{C}$ and is a substrate for the ATP-dependent proteases Lon, ClpP/X and HslVU [6]. At temperatures of $44^{\circ} \mathrm{C}$ and higher, MetA completely aggregates and is no longer found in the soluble protein fraction, thus limiting growth [9]. 
The chemical chaperone trimethylamine oxide reduces insoluble MetA accumulation and improves E. coli growth at elevated temperatures [9]. It has been suggested that MetA could be classified as a Class III substrate for chaperones because this molecule is extremely prone to aggregation [10].

Despite the importance of MetA in E. coli growth, little information exists on the amino acid residues involved in the inherent instability of MetA. The sensitivity of MetA to multiple stress conditions suggests that this enzyme might be a type of 'metabolic fuse' for the detection of unfavorable growth conditions [7]. Previously, we used random mutagenesis of metA to improve $E$. coli growth at elevated temperatures [11]. Mutations that resulted in the amino acid substitutions I229T and N267D enabled the E. coli strain WE to grow at higher temperatures and increased the ability of the strain to tolerate acidic conditions. In this study, we extended our stabilization studies using a computer-based design and consensus approach [12] to identify additional mutations that might stabilize the inherently unstable MetA enzyme. To achieve pronounced thermal stabilization, we combined several single substitutions in a multiple mutant, as the thermo-stabilization effects of individual mutations in many cases were independent and nearly additive [12]. Here, we describe the successful application of the consensus concept approach and the I-mutant2.0 modeling tool [13] to design stabilized MetA mutants. The consensus concept approach for engineering thermally stable proteins is based on an idea that by multiple sequence alignment of the homologous counterparts from mesophiles and thermophiles, the nonconsensus amino acid might be determined and substituted with the respective consensus amino acid, contributing to the protein stability [12]. I-Mutant2.0 is a support vector machine-based web server for the automatic prediction of protein stability changes with single-site mutations (http://gpcr.biocomp.unibo. it/ emidio/I-Mutant2.0/I-Mutant2.0_Details.html).

Four substitutions, Q96K, I124L, I229Y and F247Y, improved the growth of the E. coli WE strain at elevated temperatures. Unexpectedly, the MetA mutants I124Y and I229Y, which conferred higher growth rates at $44^{\circ} \mathrm{C}$, displayed melting temperatures similar to that of the native enzyme but exhibited improved in vivo stability. The stabilized MetA mutant enzymes at least partially recovered the growth defects of mutant $E$. coli strains with deletions of either ATP-dependent proteases or the DnaK chaperone. These results suggest that the growth defects of $\Delta d n a K$ or protease-deficient mutants primarily reflect malfunctioning MetA at $37^{\circ} \mathrm{C}$, a standard physiological temperature. Consistently, the addition of methionine recovered the temperaturedependent growth defects of these mutants.

\section{Results}

Mutant MetAs enable $E$. coli growth at elevated temperatures

Previously, we identified two amino acid substitutions, I229T and N267D, which conferred stability to the MetA protein [11]. To obtain additional stable MetA mutants, we employed a multiple alignment approach and identified eight amino acid residues present in all thermophilic MetAs but absent in E. coli MetA (Additional file 1: Figure S1). The metA mutations that resulted in the corresponding amino acid substitutions Q96K, L110V, I124L, R160L, A195T, A200E, D218G and F247Y were integrated into the $E$. coli JW3973 ( $\Delta$ metA) chromosome to yield the strains K96, V110, L124, L160, T195, E200, G218 and Y247, respectively. Among the constructed strains, three mutants, K96, L124 and Y247, demonstrated accelerated growth at $44^{\circ} \mathrm{C}$ in $\mathrm{M} 9$ glucose medium (Figure 1; Additional file 2: Table S1) compared with the control strain WE, which harbored the wild-type metA gene from the E. coli K-12 strain W3110 [11].

Using the I-Mutant2.0 modeling tool [13] for protein stability prediction, the I229Y mutation was predicted to improve MetA stability and accelerate growth at $44^{\circ} \mathrm{C}$

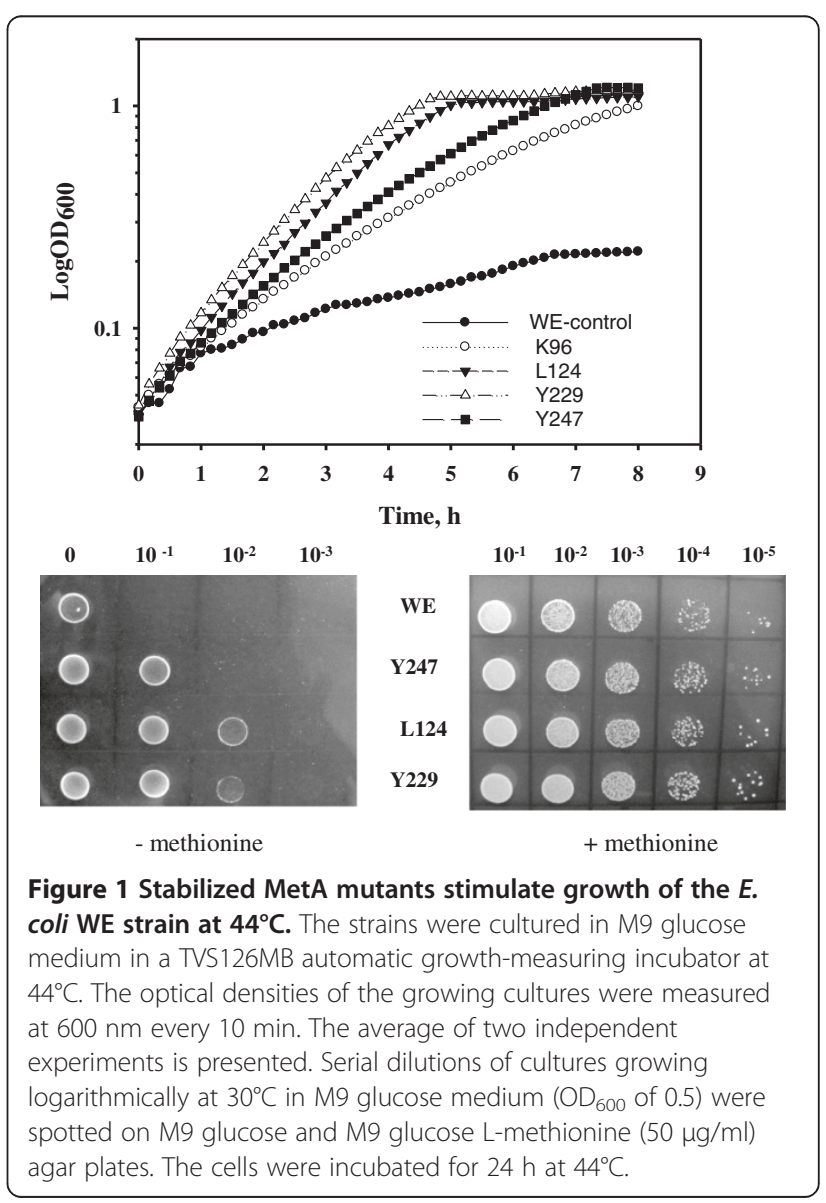


thermo-tolerant growth of the L124, Y229 and Y247 mutants, the serially diluted cultures were incubated on solid M9 glucose plates at $44^{\circ} \mathrm{C}$ (Figure 1). The viability of the mutant strains was increased by at least one to two orders of magnitude compared with the wild-type strain (Figure 1). Supplementation of the culture medium with L-methionine stimulated the growth of the wild-type and the mutant strains at $44^{\circ} \mathrm{C}$ to the same extent, thus abolishing the differences between the wild-type and mutant strains (Figure 1). The mutant strains L124 and Y229, which displayed the higher growth rates at $44^{\circ} \mathrm{C}$ (Additional file 2: Table S1), were selected for further analysis.

To test the combinatorial effects of the mutations, we constructed mutant strains harboring I124L-I229Y and I124L-I229Y-N267D substitutions in the MetA enzyme (designated as LY and LYD, respectively). The N267D substitution conferring an increased thermal stability to the MetA enzyme has been previously described [11]. The double LY and triple LYD mutant strains were cultured at $45^{\circ} \mathrm{C}$ in $\mathrm{M} 9$ glucose medium and compared with single mutants L124 and Y229 and the wild-type strain WE (Additional file 3: Figure S2). The temperature $45^{\circ} \mathrm{C}$ was chosen because no significant differences between the strains harboring single and multiple mutated MetA enzymes were detected at $44^{\circ} \mathrm{C}$ (data not shown). The wild-type strain did not grow at $45^{\circ} \mathrm{C}$ (Additional file 3: Figure S2). The double LY and triple LYD mutants grew faster than the single mutant strains L124 and Y229, which had specific growth rates of 0.37 and $0.42 \mathrm{~h}^{-1}$ versus 0.18 and $0.3 \mathrm{~h}^{-1}$, respectively. The highest growth rate at $45^{\circ} \mathrm{C}$ was observed in the LYD strain $\left(0.42 \mathrm{~h}^{-1}\right)$, in which the effects of the MetA enzyme were combined the maximal number of the stabilizing mutations. However, the mutant LYD still grew slower than in the presence of L-methionine (specific growth rate $0.53 \mathrm{~h}^{-1}$; data not shown). This result might reflect the presence of another thermolabile protein in the methionine biosynthetic pathway. Previously, Mogk et al. [14] showed that MetE, which catalyzes the last step in methionine biosynthesis, was also thermally sensitive and tended to form aggregates at a $45^{\circ} \mathrm{C}$ heat shock.

\section{Mutant MetAs enabling E. coli growth at higher temperatures did not display an increased thermal transition midpoint}

To determine whether the accelerated growth observed at $44^{\circ} \mathrm{C}$ for the single mutant MetA strains is due to increased thermal stability of MetA, the protein melting temperature $\left(T_{\mathrm{m}}\right)$ was measured using differential scanning calorimetry (DSC). The wild-type and mutant MetA enzymes containing a C-terminal six-histidine tag were purified as described in the Methods section. The $T_{\mathrm{m}}$ of the wild-type MetA was $47.07 \pm 0.01^{\circ} \mathrm{C}$ (Table 1), and the
Table 1 Differential scanning calorimetric data for the wild- type and mutant MetA enzymes

\begin{tabular}{lllll}
\hline Enzyme & $\boldsymbol{T}_{\mathbf{m}}\left({ }^{\circ} \mathbf{C}\right)$ & $\Delta \mathbf{H}^{*}$ & $\Delta \mathbf{H}_{\mathbf{v}}^{*}$ & $\Delta \mathbf{H} / \Delta \mathbf{H}_{\mathbf{v}}$ \\
\hline MetA, wt & $47.01 \pm 0.26$ & $5.93 \times 10^{4}$ & $1.18 \times 10^{5}$ & 0.5 \\
\hline I124L & $48.65 \pm 0.06$ & $6.51 \times 10^{4}$ & $1.86 \times 10^{5}$ & 0.35 \\
\hline I229Y & $50.68 \pm 0.06$ & $8.99 \times 10^{4}$ & $2.38 \times 10^{5}$ & 0.38
\end{tabular}

*The errors associated with the data were $<2 \%$ for $\Delta \mathrm{H}$ and $\Delta \mathrm{H}_{\mathrm{v}}$. The calorimetric heat $(\Delta \mathrm{H})$ is the heat change per mole of enzyme. The van't Hoff heat $\left(\Delta \mathrm{H}_{\mathrm{v}}\right)$ is the heat change per cooperative unit. The ratio $\Delta \mathrm{H} / \Delta \mathrm{H}_{\mathrm{v}}$ is a measure of the number of thermally transited cooperative units per mole of enzyme. All measurements were performed in triplicate.

$T_{\mathrm{m}} \mathrm{s}$ of the stabilized MetA proteins were slightly higher than that of the wild-type enzyme (Table 1).

Because the stabilized mutants displayed $T_{\mathrm{m}}$ values similar to the native enzyme, we hypothesized that the catalytic activity was enhanced in the MetA mutants. No difference was observed in the $k_{\text {cat }}$ and $K \mathrm{~m}$ values for succinyl-CoA between the stabilized MetA mutants and native MetA enzyme, whereas the $\mathrm{Km}$ for L-homoserine was reduced 1.5-fold in the $1124 \mathrm{~L}$ mutant compared with the wild-type MetA (Table 2). This finding is consistent with the slight increase in $k_{\text {cat }} / K \mathrm{~m}$ of $58 \%$ compared with the native enzyme. Thus, the stabilizing mutations had little to no effect on the catalytic activity of the MetA enzyme.

MetA mutant enzymes exhibit reduced aggregation at an elevated temperature $\left(45^{\circ} \mathrm{C}\right)$ in vitro and in vivo

Native MetA was previously reported to become completely aggregated in vitro at temperatures of $44^{\circ} \mathrm{C}$ and higher [9]. To examine the aggregation-prone behavior of native and stabilized MetAs, we generated in vitro aggregates of the purified proteins as described in the Methods section. The native MetA enzyme was completely aggregated after heating at $45^{\circ} \mathrm{C}$ for $30 \mathrm{~min}$ (Figure 2). In contrast, the engineered I124L and I229Y mutant MetAs demonstrated a higher level of aggregation resistance; only $73 \%$ of I124L and $66 \%$ of I229Y were insoluble (Figure 2).

In addition, we examined the level of soluble MetA enzymes in vivo after heat shock at $45^{\circ} \mathrm{C}$ for $30 \mathrm{~min}$ (Additional file 4: Figure S3). The amount of the native MetA protein in the soluble fraction decreased to $52 \%$ following heat shock, whereas the relative amounts of soluble MetA I124L and I229Y mutants were $76 \%$ and $68 \%$, respectively. The amount of insoluble native MetA protein increased 28-fold after heating, while those of stabilized MetA I124L and I229Y mutants increased 20- and 17-fold, respectively (Additional file 4: Figure S3). These results confirmed the higher resistance of the stabilized I124L and I229Y mutant enzymes to aggregation. 
Table 2 Kinetic parameters of the wild-type and stabilized MetA enzymes

\begin{tabular}{|c|c|c|c|c|c|}
\hline \multirow[t]{2}{*}{ Enzyme } & \multirow[t]{2}{*}{$k_{\text {cat }}\left(\mathrm{s}^{-1}\right)$} & \multicolumn{2}{|c|}{ Succinyl-CoA } & \multicolumn{2}{|c|}{ L-homoserine } \\
\hline & & $K_{\mathrm{m}}(\mathrm{mM})$ & $k_{\mathrm{cat}} / K_{\mathrm{M}}\left(\mathrm{M}^{-1} \mathrm{~s}^{-1}\right)$ & $K_{\mathrm{m}}(\mathrm{mM})$ & $k_{\text {cat }} / K_{M}\left(M^{-1} s^{-1}\right)$ \\
\hline MetA, wt & $36.72 \pm 0.9$ & $0.37 \pm 0.05$ & $9.9^{*} 10^{4}$ & $1.25 \pm 0.3$ & $2.93^{*} 10^{4}$ \\
\hline I124L & $38.59 \pm 0.5$ & $0.38 \pm 0.06$ & $1.02 * 10^{5}$ & $0.83 \pm 0.15$ & $4.65^{*} 10^{4}$ \\
\hline $229 Y$ & $39.28 \pm 0.5$ & $0.36 \pm 0.06$ & $1.09 * 10^{5}$ & $1.42 \pm 0.1$ & $2.76^{*} 10^{4}$ \\
\hline
\end{tabular}

MetA mutant enzymes are more stable in vivo at normal $\left(37^{\circ} \mathrm{C}\right)$ and elevated $\left(44^{\circ} \mathrm{C}\right)$ temperatures

To determine the effects of these mutations on MetA stability in vivo, we analyzed the degradation of the mutant and native MetA enzymes after blocking protein synthesis using chloramphenicol. The residual MetA in the cells was quantified through Western blotting as described in the Methods section. As shown in Figure 3, the I124L and I229L MetA mutants were approximately 2-3-fold more stable than native MetA, with half-lives $\left(\mathrm{t}_{1 / 2}\right)$ of $87 \mathrm{~min}(\mathrm{I} 124 \mathrm{~L})$ and $107 \mathrm{~min}(\mathrm{I} 229 \mathrm{~L})$ at $37^{\circ} \mathrm{C}$ and $52 \mathrm{~min}(\mathrm{I} 124 \mathrm{~L})$ and $57 \mathrm{~min}(\mathrm{I} 229 \mathrm{~L})$ at $44^{\circ} \mathrm{C}$, respectively; the half-life of the native MetA was $36 \mathrm{~min}$ at $37^{\circ} \mathrm{C}$ and $25 \mathrm{~min}$ at $44^{\circ} \mathrm{C}$.

Stabilized MetAs partially compensate the growth defects of the $\Delta$ dnaK mutants

MetA has been suggested to be classified as a Class III substrate for chaperones because this enzyme is extremely prone to aggregation [10]. Under physiological heat stress conditions, the DnaK system is the most

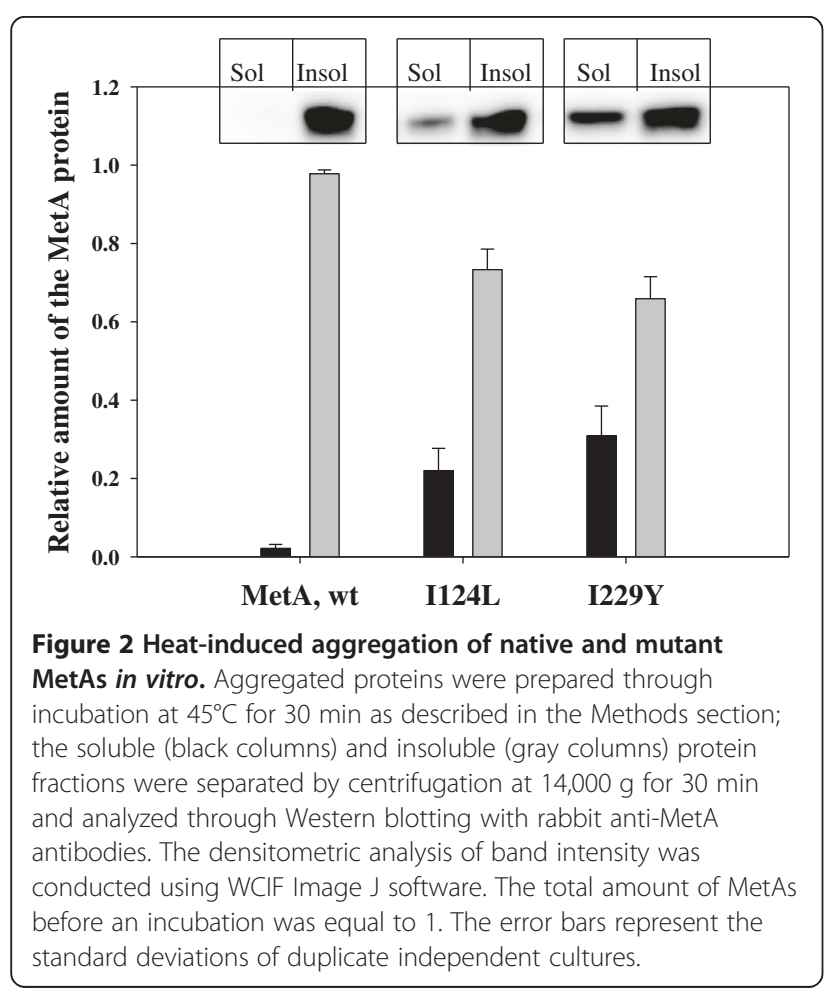

effective chaperone for preventing the aggregation of thermolabile proteins [14]. Thus, the $\Delta$ dnaK52 mutant strain displays a slower growth rate at $37^{\circ} \mathrm{C}$ and no growth at $42^{\circ} \mathrm{C}$ [15]. Because MetA is one of the most thermolabile proteins, we determined the growth profiles of dnaK null mutants expressing stabilized MetAs. We constructed the WE $\Delta d n a K, \mathrm{~L} 124 \Delta d n a K$ and Y229 d naK mutant strains and cultured these cells in M9 glucose medium at $37^{\circ} \mathrm{C}$. As shown in Figure 4, the mutant strain Y229 $\Delta$ dnaK grew 26\% faster than the control strain WE $\Delta d n a K$, with a growth rate of $0.48 \mathrm{~h}^{-1}$ for Y229 $\Delta$ dnaK and $0.38 \mathrm{~h}^{-1}$ for WE $\Delta$ dnaK (see Additional file 5: Table $\mathrm{S} 2$ for the specific growth rates). The mutant strain L124 $\Delta d n a K$ grew at the same rate as Y229 $\Delta$ dnaK. We observed an increased accumulation of insoluble wild-type MetA in heat-stressed $\Delta d n a K$ cells compared with the mutated I124L and I229Y enzymes, which had relative amounts of $57 \%$ and $33 \%$ of the wild-type enzyme, respectively (Additional file 6: Figure S4). This finding might partially explain the slower growth of the WE $\Delta d n a K$ strain due to an increased aggregation of the wild-type MetA compared with the I124L and I229Y mutants.

Despite an accelerated growth, the Y229 $\Delta$ dnaK mutant strain did not achieve the same growth rate as the dnaK+ parental strain (Figure 4), potentially reflecting increased misfolding and the aggregation of other proteins in the absence the DnaK chaperone. We also examined the viability of serially diluted WE $\Delta$ dnaK and Y229 $\Delta$ dnaK cultures at $37^{\circ} \mathrm{C}$ and confirmed the accelerated growth of the stabilized MetA mutant Y229 $\Delta d n a K$ (Figure 4). At $42^{\circ} \mathrm{C}$, the non-permissive growth temperature for the $\Delta d n a K \mathrm{mu}-$ tants, no growth occurred, even in the presence of the stabilized MetA mutants (data not shown).

Partial recovery of the impaired growth of protease-null mutants by the stabilized MetAs

Previous findings have revealed that the temperaturedependent unfolding of MetA resulted in the proteolysis of this enzyme [6]. Aggregated MetA is degraded by a combination of the ATP-dependent cytosolic proteases Lon, ClpPX/PA and HslVU, particularly at higher temperatures [6]. Because MetA is an inherently unstable protein, we reasoned that aggregated MetAs should be degraded by intracellular proteases and that proteaseminus mutant, unable to degrade aggregated MetAs, 

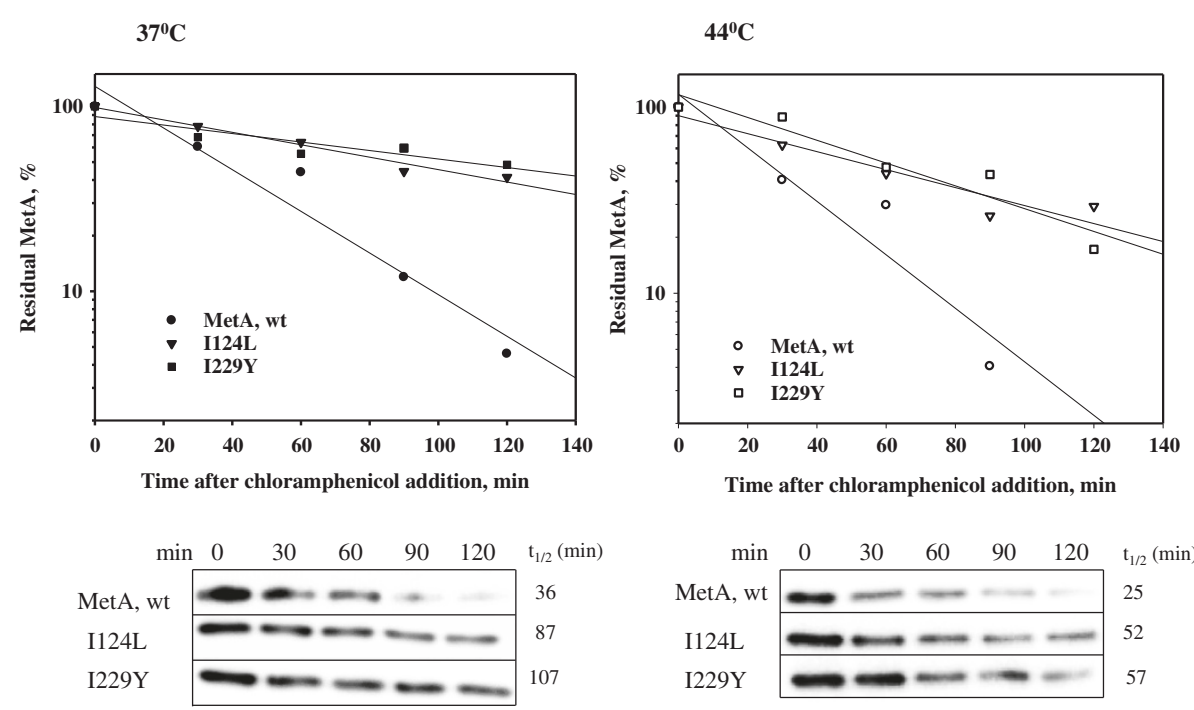

Figure 3 In vivo stability of MetA mutants. Cells of the strains WE, L124 and $Y 229$ exponentially growing $\left(\mathrm{OD}_{600}=0.3\right)$ at $37^{\circ} \mathrm{C}$ in $\mathrm{M} 9$ medium were treated with $200 \mathrm{\mu g} / \mathrm{ml}$ of chloramphenicol. The cultures were divided; one half of each culture was maintained at $37^{\circ} \mathrm{C}$ (solid symbols), and the other half of the culture was shifted to $44^{\circ} \mathrm{C}$ (open symbols). The samples were collected at the indicated time points and analyzed through Western blotting as described in the Methods section. Densitometry results were normalized after setting the MetA amount before chloramphenicol addition equal to $100 \%$.

would display hampered growth. The stabilized MetAs displaying higher in vivo stability would improve the growth of E. coli protease-negative mutants. The triple protease-deficient mutants $\mathrm{WE}\left(\mathrm{P}^{-}\right), \mathrm{L} 124\left(\mathrm{P}^{-}\right)$and $\mathrm{Y} 229$ $\left(\mathrm{P}^{-}\right)$were constructed and cultured at $42^{\circ} \mathrm{C}$ in $\mathrm{M} 9$ glucose-defined medium. Kanemori et al. [16] demonstrated the temperature-sensitive growth of the triple protease-deficient E. coli mutant $\mathrm{KY} 2266$ at $42^{\circ} \mathrm{C}$. As shown in Figure 4, the mutant $\mathrm{Y} 229\left(\mathrm{P}^{-}\right)$exhibited an increased specific growth rate $(\mu)$ of $0.25 \mathrm{~h}^{-1}$ compared with a growth rate of $0.096 \mathrm{~h}^{-1}$ for the control strain $\mathrm{WE}\left(\mathrm{P}^{-}\right)$. The growth rate of $\mathrm{L} 124\left(\mathrm{P}^{-}\right)$was similar to that of Y229( $\left(\mathrm{P}^{-}\right)$(Additional file 5: Table S3). These results indicate that the growth defect of the protease-deficient mutant might be a consequence of increased accumulation of the aggregated MetA proteins. Previously, Biran et al. [6] showed that the native MetA was stabilized in the cells of triple deletion mutant lon, clpP, hslVU. However, these authors did not identify which protein fraction, soluble or insoluble, contained the MetA. Apparently, an excess of the MetA synthesized at elevated temperatures in a proteolysis-minus background leads to the accumulation of insoluble aggregates that are toxic to the cells and inhibit bacterial growth. Therefore, we examined the in vivo aggregation of the wild-type and mutated MetA enzymes in heat-stressed proteasedeficient cells. The relative amounts of MetA insoluble aggregates in the stabilized I124L and I229Y mutants were reduced to $59 \%$ and $44 \%$, respectively, compared with wild-type MetA (Additional file 6: Figure S4). We assume that the stabilized MetAs remaining soluble and functionally active relieved the growth inhibition of the protease-negative $E$. coli mutant.

We also examine whether the stabilized MetAs affect the viability of protease-deficient strains at an elevated temperature $\left(42^{\circ} \mathrm{C}\right)$. The mutant $\mathrm{Y} 229\left(\mathrm{P}^{-}\right)$was at least 10 fold more viable than the control strain $\mathrm{WE}\left(\mathrm{P}^{-}\right)$(Figure 4). The same result was observed for the mutant L124( $\left(\mathrm{P}^{-}\right)$ (data not shown). However, despite accelerated growth and increased viability, the protease-deficient mutants harboring the stabilized MetAs grew slower than the protease-positive strains WE and Y229 (Figure 4). Our findings indicate that the growth defect in the proteasenull mutant strain is partially due to MetA instability.

\section{Methionine recovers the growth defect of the $E$. coli mutants lacking either ATP-dependent proteases or the DnaK chaperone}

Because the stabilized MetA mutants conferred an increased growth rate to $\Delta d n a K$ and protease-deficient $E$. coli mutants at higher temperatures, we expected that methionine supplementation might recover the growth defects of both mutants. Thus, we examined the direct effect of L-methionine supplementation on WE $\Delta$ dnaK and $\operatorname{WE}\left(\mathrm{P}^{-}\right)$growth at $37^{\circ} \mathrm{C}$ and $42^{\circ} \mathrm{C}$, respectively. In the methionine-supplemented medium, the mutants WE $\Delta d n a K$ and $W E\left(\mathrm{P}^{-}\right)$grew two- and six-fold faster, respectively, than without L-methionine supplementation (Figure 5). For WE $\Delta d n a K$, the growth rate was $0.73 \mathrm{~h}^{-1}$ with methionine and $0.38 \mathrm{~h}^{-1}$ without methionine. For 


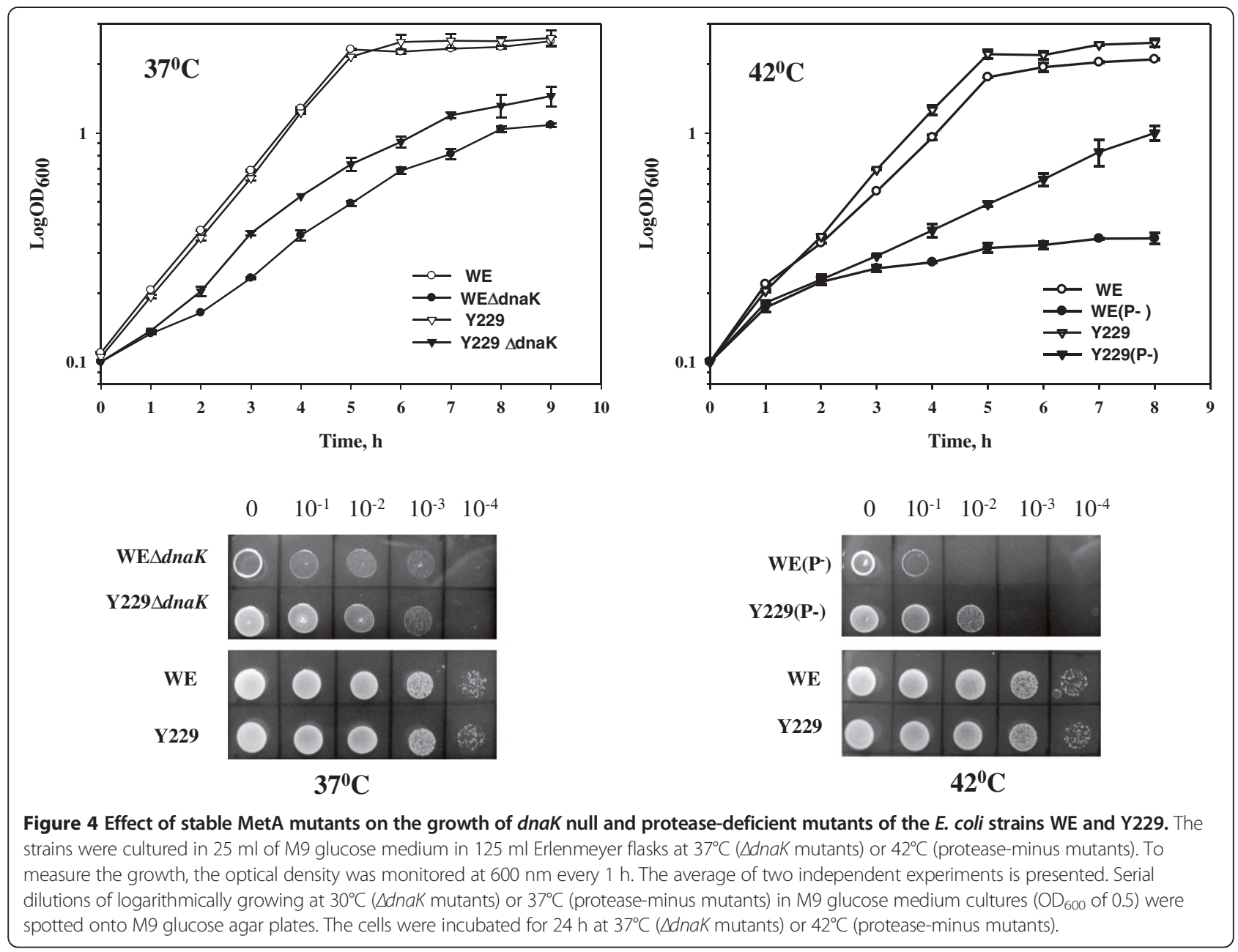

$\mathrm{WE}\left(\mathrm{P}^{-}\right)$, the growth rate was $0.58 \mathrm{~h}^{-1}$ with methionine and $0.095 \mathrm{~h}^{-1}$ without methionine (Figure 5; Additional file 5: Tables S2 and S3). The spot test confirmed the results obtained with flask-cultivation (Figure 5). Lmethionine also stimulates the growth of the control strain WE at $37^{\circ} \mathrm{C}$ and $42^{\circ} \mathrm{C}$ (Figure 5; Additional file 5: Tables S2 and S3). However, the WE strain demonstrated only a $28 \%$ and $44 \%$ increase of the specific growth rates at $37^{\circ} \mathrm{C}$ and $42^{\circ} \mathrm{C}$, respectively, in the presence of methionine $\left(0.77\right.$ and $0.6 \mathrm{~h}^{-1}$ at $37^{\circ} \mathrm{C} ; 0.78$ and $0.54 \mathrm{~h}^{-1}$ at $42^{\circ} \mathrm{C}$ with and without methionine supplementation, respectively; Additional file 5: Tables S2 and S3). These results clearly indicate that an impaired methionine supply underlies the $d n a K$ - and protease-null mutant growth defects.

To determine the effect of methionine on the growth of the mutated MetA strains, we cultivated the isogenic strains WE and WE $\Delta d n a K$ and Y229 and Y229 d dnaK in the presence of methionine at $37^{\circ} \mathrm{C}$ (Additional file 7: Figure S5). In the methionine- supplemented medium, the $\Delta d n a K$ mutants grew at equal rates, and only slightly slower growth than the $d n a K+$ strains was observed
(Additional file 5: Table S2; Additional file 7: Figure S5). These findings suggest that a malfunction of the methionine biosynthetic enzymes, including MetA, is primarily responsible for the impaired growth of the $\Delta d n a K$ mutant strains at $37^{\circ} \mathrm{C}$. At temperatures higher than $37^{\circ} \mathrm{C}$, defects in other factors, such as chromosomal partitioning, extensive filamentation and increased levels of heat-shock protein (HSP) biosynthesis, might significantly hamper the growth of the $\Delta d n a K$ mutants, as previously shown for the $\Delta d n a K 52$ mutant strain [15].

L-methionine also eliminated the difference in the growth rates between the protease- deficient control $\mathrm{WE}\left(\mathrm{P}^{-}\right)$and mutant $\mathrm{Y} 229\left(\mathrm{P}^{-}\right)$strains $\left(0.58\right.$ and $0.59 \mathrm{~h}^{-1}$, respectively) at $42^{\circ} \mathrm{C}$ (Additional file 5: Table S3; Additional file 7: Figure S5). However, the protease-negative mutants grew $25 \%$ slower than the parent strains in the presence of L-methionine (Additional file 5: Table S3; Additional file 7: Figure S5), potentially reflecting the accumulation of other protein aggregates [17].

A partial complementation of the impaired growth of the $\Delta d n a K$ and protease-negative strains through stabilized MetAs indicates that the inherent instability of 


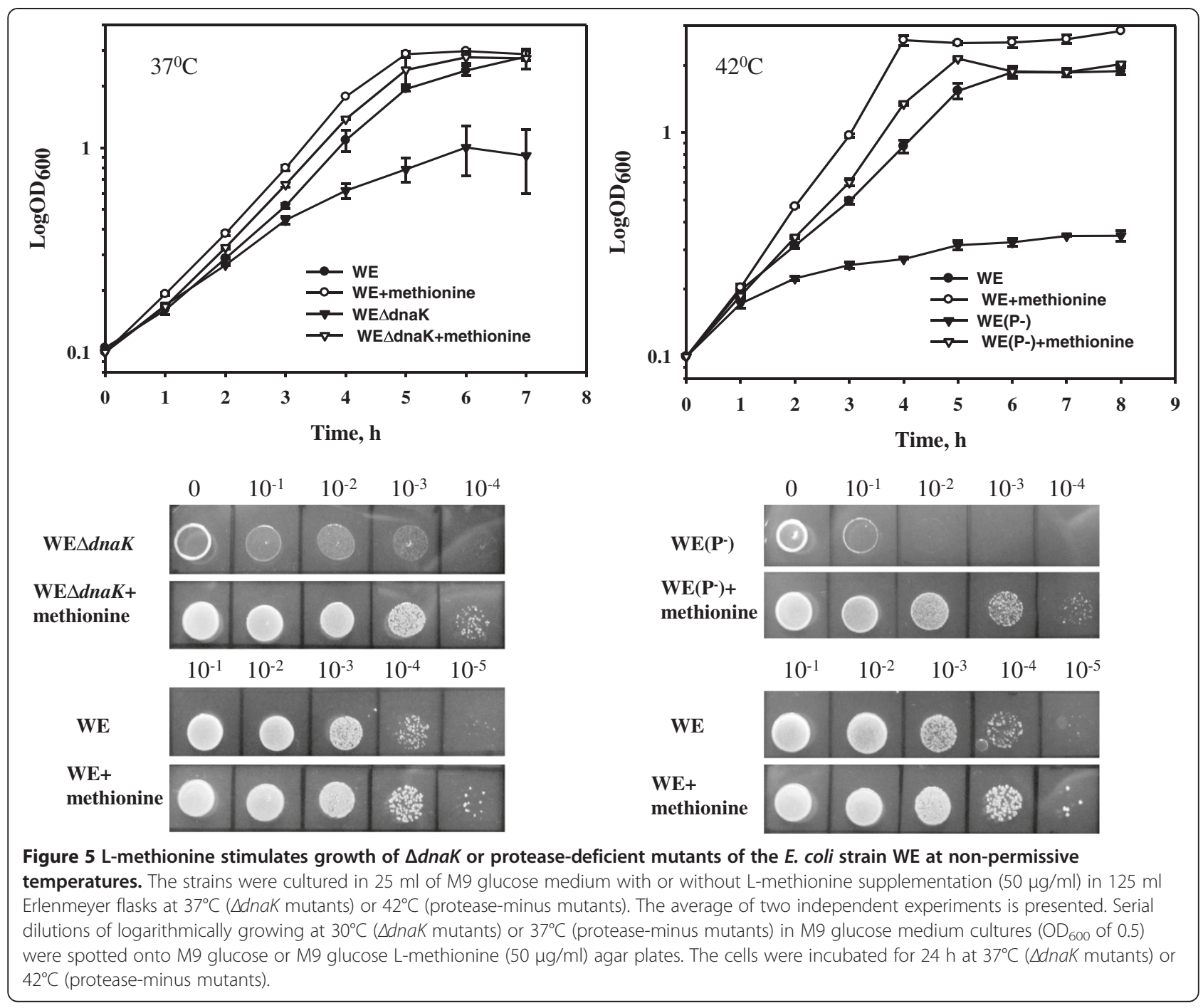

MetA plays a significant role in the growth defects observed in these mutant strains.

\section{Discussion}

The growth of E. coli strains at elevated temperatures in a defined medium is impaired by the extreme instability of the first enzyme in the methionine biosynthetic pathway, homoserine o-succinyltransferase (MetA) [18]. Although the key role of the MetA protein in E. coli growth under thermal stress has been known for 40 years [8], it is unclear which residues are involved in the inherent instability of MetA. Previously, we identified two amino acid substitutions, I229T and N267D, responsible for MetA tolerance to both thermal and acid stress [11]. In this study, we employed several approaches to design more stable MetA proteins. Using the consensus concept approach [12], stabilization was achieved through three single amino acid substitutions, Q96K, I124L and F247Y.
We hypothesized that a combination of these amino acid substitutions might significantly increase MetA stability compared with the single mutants we identified in the randomly mutated thermotolerant MetA-333 [11]. The new MetA mutant enzymes were more resistant to heatinduced aggregation in vitro (Figure 2). The enhanced in vivo stabilities of the MetA mutants were also demonstrated through the immunodetection of residual MetA protein after blocking protein synthesis (Figure 3). However, the melting temperature, a good indicator of thermal stability [19], was only slightly increased. Instead of thermo-stabilization, the mutant MetAs might experience kinetic stabilization, in which a specific conformation change, which increases the unfolding barrier, ultimately results in slow unfolding rates [20]. This assumption is supported by a decreased level of the mutated MetAs observed in insoluble protein fraction under a temperature shift from $30^{\circ}$ to $45^{\circ} \mathrm{C}$ compared with the native MetA 
protein (Additional file 4: Figure S3). If a native protein is thermodynamically unstable and/or functions under stress conditions, then kinetic stabilization could enhance the functional properties of the protein [21]. Furthermore, improved kinetic stability is tightly associated with protease resistance [22]. Notably, the MetA mutants were more resistant to proteases; in vitro reconstitution experiments confirmed the resistance of the MetA mutants to the ATP-dependent cytosolic proteases, including Lon, ClpPX/ PA and HslVU (Figure 6). Previously, the aggregated MetA protein was identified as a substrate for intracellular proteases Lon, ClpPX/PA and HslVU [6]. Biran et al. [6] assumed the combinatorial action of these proteases on MetA degradation because the protein stabilization was detected in the triple deletion mutant lon, clpP, hslVU but not in any single (lon, clpP, hflB and hslVU) or double $($ lon-clpP) deletion mutants.

Previous studies have shown that the $d n a K$ gene is not essential for growth and protein folding at $30^{\circ} \mathrm{C}$ but is required at temperatures above $37^{\circ} \mathrm{C}$ or below $15^{\circ} \mathrm{C}$ [23]. Here, we showed that the defective growth of a $\Delta d n a K$ mutant at $37^{\circ} \mathrm{C}$ can be partially restored using a stabilized
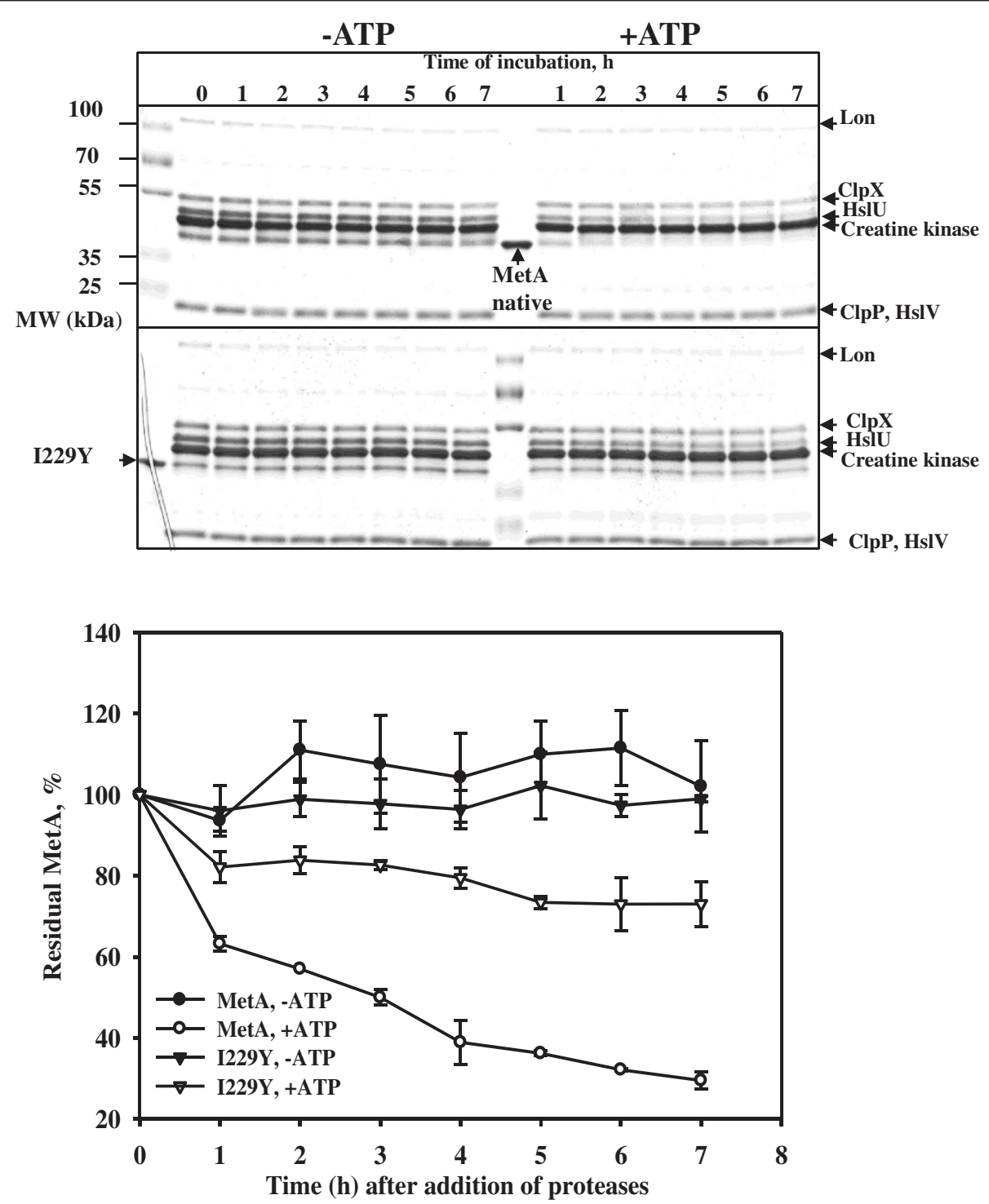

Figure 6 In vitro degradation of the native MetA protein and stabilized I229Y mutant by the ATP-dependent proteases Lon, ClpP/X and HsIVU. Degradation reactions were performed at $37^{\circ} \mathrm{C}$ with or without ATP as described in the Methods section. Untreated proteins indicate the positions of native MetA (the central lane of the upper gel) and mutant I229Y (the left lane of the lower gel). Densitometry results were normalized after setting the MetA amount before ATP addition equal to 100\%. The results are plotted as the mean and standard deviation of two independent experiments. 
MetA (Figure 4). This result suggests that the growth defect of the DnaK-deficient strain is primarily due to non-functional MetA because MetA, an inherently unstable protein even at the physiological temperature of $37^{\circ} \mathrm{C}$, requires folding assistance from the DnaK chaperone system. The stabilized MetA mutants also partially restore the growth defects of protease-deficient strains at $42^{\circ} \mathrm{C}$ (Figure 4). We also examined whether the temperaturesensitive mutations $(\Delta m u k B, \Delta b a m E$ and $\Delta l p p)$ affecting other cellular processes are suppressed through methionine supplementation at higher temperatures. None of the mutants showed improved growth, indicating that proper methionine supply is a major issue in the growth defects of both a $\Delta d n a K$ and the triple protease mutants.

Taken together, these results suggest that the temperaturedependent growth defects of the $\Delta d n a K$ mutants and protease-deficient strains primarily reflect the malfunction of MetA and consequently, the methionine supply. Furthermore, the addition of methionine completely corrects the growth defect of the dnaK null mutant at $37^{\circ} \mathrm{C}$ and recovers most of the impaired growth of the protease-deficient strain at $42^{\circ} \mathrm{C}$.

To evaluate the conformational changes caused by single-site mutations in the MetA protein, we performed molecular dynamics simulations of a homology model based on the closest MetA homolog, homoserine Osuccinyltransferase from Thermotoga maritima (PDB code $2 \mathrm{H} 2 \mathrm{~W})$. Our model has shown that the stabilizing MetA mutations were randomly distributed in different secondary structure elements (Additional file 8: Table S5). Stabilization has been shown for these mutants according to the altered free energy of protein folding $(\Delta \Delta G<$ $-1 \mathrm{kcal} / \mathrm{mol}$ ) (Additional file 8: Table S5). We observed that the highest $\Delta \Delta \mathrm{G}$ value was correlated with the maximal melting temperature $\left(\mathrm{T}_{m}\right)$ for the Y229 mutant (Table 1; Additional file 8: Table S5). We also calculated the cavity volume change as a parameter associated with the conformational stability and folding reaction [24]. The cavity volumes of all mutants were diminished compared with the native enzyme, with maximal decrease for the I229Y substitution (Additional file 8: Table S5). Cavities in proteins are a major contributor to low packing densities and reduced stability [25]. Cavities and surface grooves are also potential sites for the binding of drugs, ligands and other proteins [26]. Therefore, decreased cavity volumes should lead to higher conformational stability and resistance to aggregation for originally unstable proteins, such as MetA. Thus, MetA might be an inherently unstable protein [27] because it unfolds at room temperature and dramatically loses activity at $30^{\circ} \mathrm{C}$ or higher [9]. Due to its increased sensitivity to many stress conditions, including temperature, weak organic acids and oxidative stress [7], MetA protein has been suggested to function as a 'metabolic fuse' to detect unfavorable growth conditions [7].

\section{Conclusions}

In this study, we further elucidated the mutations in MetA that facilitate faster $E$. coli growth at elevated temperatures $\left(44^{\circ} \mathrm{C}\right)$ compared with the wild-type enzyme. Stabilized MetA proteins partially suppressed the temperaturesensitive phenotype of both $d n a K$ and triple protease deficient mutants. Because improving the growth of $E$. coli at higher temperatures has an immediate application in realizing the bacterial cell factory, this improvement might also facilitate the identification of target genes and proteins, enabling thermotolerance or improved growth at higher operating temperatures [28-30].

\section{Methods}

\section{Strains and culture conditions}

The strains and plasmids used in this study are listed in Table 3.

The E. coli strains were grown in minimal M9 medium [31] supplemented with glucose $(0.2 \%)$ or in rich LB medium (Difco Laboratories, Detroit, USA). Antibiotics were used at the following concentrations: ampicillin, 100 $\mu \mathrm{g} / \mathrm{ml}$; chloramphenicol, $20 \mu \mathrm{g} / \mathrm{ml}$; kanamycin, $25 \mu \mathrm{g} / \mathrm{ml}$; and tetracycline, $10 \mu \mathrm{g} / \mathrm{ml}$. L-methionine was added to the medium at a final concentration of $50 \mu \mathrm{g} / \mathrm{ml}$. The growth of $E$. coli strains in M9 glucose medium at different temperatures was assessed using a TVS126MB automatic growth-measuring incubator (Advantec MFS Inc., Tokyo, Japan). The optical density of the growing cultures was measured at $600 \mathrm{~nm}$ every $10 \mathrm{~min}$.

\section{Site-directed mutagenesis of met $A$}

Site-directed mutagenesis was performed using a KODPlus-Mutagenesis Kit (Toyobo, Osaka, Japan) according to the manufacturer's protocol. The plasmid pMetA [11] served as a template, and the primers are shown in Table S6 (Additional file 9). The mutant I229Y was constructed through overlap extension PCR using a QuickChange II-E Site-Directed Mutagenesis Kit (Stratagene, La Jolla, USA) with the primer pair MetY-forward (GCCAGTAAAGA TAAGCGCTACGCCTTTGTGACGGG) and MetY-reverse, which is the complement of the forward primer. Changes in the sequence are shown in italic letters.

\section{Incorporation of the metA mutations into the $E$. coli chromosome}

The mutated metA genes were transferred to the $E$. coli JW3973 ( $\Delta$ metA) chromosome as previously described [11] using the $\lambda$ Red recombination system [32].

\section{Construction of the $\Delta d n a K:: c a t$ and [( $\Delta$ clpX-lon)::cat, $\Delta$ hsIVU1172::tet] mutants}

The structural gene $d n a K$ in the WE strain was replaced with the chloramphenicol resistance gene using the $\lambda$ Red recombination system [32]. A disruption cassette 
Table 3 Bacterial strains and plasmids used in this study

\begin{tabular}{|c|c|c|}
\hline Strain or plasmid & Relevant description $^{*}$ & Source or reference \\
\hline \multicolumn{3}{|l|}{ Escherichia coli } \\
\hline W3110 & $F-, \lambda^{-}, I N(r r n D-r r n E) 1, r p h-1$ & KCTC \\
\hline \multirow[t]{3}{*}{ JW3973 } & F-, $\Delta(\operatorname{araD}-\operatorname{araB}) 567, \Delta / a c Z 4787(: . r r n B-3)$, & Keio collection \\
\hline & $\lambda$, rph-1, $\Delta$ metA780::kan, & National Institute \\
\hline & $\Delta($ rhaD-rhaB) 568, hsdR514, & of Genetics, Japan \\
\hline WE & JW3973 carrying the wild-type metA gene & [11] \\
\hline \multirow[t]{2}{*}{ K96 } & JW3973 carrying the metA gene & This study \\
\hline & with the Q96K substitution & \\
\hline \multirow[t]{2}{*}{$\underline{\mathrm{L} 124}$} & JW3973 carrying the metA gene & This study \\
\hline & with the $1124 \mathrm{~L}$ substitution & \\
\hline \multirow[t]{2}{*}{ Y229 } & JW3973 carrying the metA gene & This study \\
\hline & with the I229Y substitution & \\
\hline \multirow[t]{2}{*}{ Y247 } & JW3973 carrying the metA gene & This study \\
\hline & with the F247Y substitution & \\
\hline \multirow[t]{2}{*}{$\underline{\text { LY }}$} & JW3973 carrying the metA gene & This study \\
\hline & with the I124L and I229Y substitutions & \\
\hline \multirow[t]{2}{*}{ LYD } & JW3973 carrying the metA gene & This study \\
\hline & with the 1124L, 1229Y and N267D substitutions & \\
\hline $\mathrm{WE}\left(\mathrm{P}^{-}\right)$ & WE ( $\Delta$ clpX-lon):::cat, $\Delta$ hsIVU1172::tet & This study \\
\hline $\mathrm{L} 124\left(\mathrm{P}^{-}\right)$ & L124 (AclpX-lon):::cat, $\Delta$ hsIVU1172::tet & This study \\
\hline Y229(P-) & 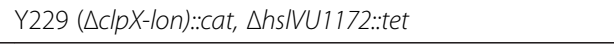 & This study \\
\hline WE $\Delta$ dnaK & WE $\triangle$ dnaK::cat & This study \\
\hline L124 $\triangle$ dnaK & L124هdnaK::cat & This study \\
\hline Y229 dnaK & Y229 ddnaK::cat & This study \\
\hline BL21(DE3) & F- ompT hsdS $S_{B}\left(r_{-B} m-B\right) g a l d c m(D E 3)$ & Novagen (Billerica, USA) \\
\hline ME7970 & $\Delta h s$ IVU1172::tet & National Institute \\
\hline (KY2966) & & of Genetics, Japan \\
\hline \multicolumn{3}{|l|}{ Plasmids } \\
\hline pKD46 & $\lambda$ Red (gam bet exo) ara C rep101(Ts), Ap ${ }^{r}$ & [32] \\
\hline \multirow[t]{2}{*}{ pMetA } & pACYC177 carrying the wild-type metA & {$[11]$} \\
\hline & under the natural $\mathrm{P}_{\text {metA }}$ promoter, $A p^{r}$ & \\
\hline \multirow[t]{2}{*}{ pDnak } & pACYC177 carrying the dnaK gene & This study \\
\hline & under the natural $P_{d n a k}$ promoter, $A p^{r}$ & \\
\hline \multirow[t]{2}{*}{ pPP1 } & pACYC177 carrying the clpX-lon genes & This study \\
\hline & under the natural $P_{c \mid p X}$ promoter, $A p^{r}$ & \\
\hline pET22b/MetA & Contains the wild-type metA gene, $\mathrm{Ap}^{\mathrm{r}}$ & [11] \\
\hline pET22b/MetAL124 & Contains the metA gene with $1124 \mathrm{~L}$ substitution, $\mathrm{Ap}^{\mathrm{r}}$ & This study \\
\hline pET22b/MetAY229 & Contains the metA gene with I229Y substitution, $\mathrm{Ap}^{r}$ & This study \\
\hline
\end{tabular}

${ }^{*} A p^{r}$ ampicillin resistance, cat chloramphenicol resistance gene, kan kanamycin resistance gene, tet tetracycline resistance gene.

was synthesized through PCR using the forward primer dnaK1 (CAGACTCACAACCACATGATGACCGAATA TATAGTGGAGACGTTTAGGTTGGCAGCATCACCCGAC), the reverse primer dnaK2 (CTTCTTCAAATT CAGCGTCGACAACATCGTCATCTTTCGCGTTGTT TGCGTAGCACCAGGCGTTTAAGG), Vent polymerase and the plasmid pACYC184 as a template (homologous sequences are shown in italic letters). Replacement of the dnaK gene was confirmed through PCR analysis of the chromosomal DNA of the WE $\Delta d n a K$ strain. A temperature-sensitive phenotype of strain WE $\Delta d n a K$ at 37 and $40^{\circ} \mathrm{C}$ (data not shown) was rescued with the plasmid pDnak carrying the $d n a K$ gene under the endogenous $\mathrm{P}_{\text {dnaK }}$ promoter amplified from the genomic DNA of WE strain using the primers dnaK3 (CGCCTCCTCGAG CATATCGCGAAATTTCTGCGC) and dnaK4 (CCCGT 
GTCAGTATAATTACCC) and cloned into the XhoI/ SmaI restriction sites of the plasmid vector pACYC177. The $\Delta$ dnaK::cat mutants of strains L124 and Y229 were obtained through transduction with P1vir using the WE $\Delta$ dnaK donor strain.

The double mutant $\Delta$ clpX-lon::cat was constructed after replacing the structural genes in the WE strain with the chloramphenicol resistance gene as previously described [32]. The primers ClpX1-forward (GCATTTGC GTCGTCGTGTGCGGCACAAAGAACAAAGAAGAGGTTTTGACCCGTTGGCAGCATCACCCGAC) and Lon1-reverse (CCTCAATGCGCTTCACAGGATGA ATGTCCAGATCGGCAATTACGTTGTCAGGGTAGCACCAGGCGTTTAAGG), Vent polymerase and the plasmid pACYC184 were used to synthesize the chloramphenicol resistance gene flanked by the 51 nucleotides upstream of the $\operatorname{clp} X$ gene and the 52 nucleotides corresponding with the region 2241-2293 of the lon gene (homologous sequences are underlined). The gene hslVU in the double mutant $\Delta c l p X-l o n$ was replaced through transduction using P1vir grown on the $\Delta$ hslVU1172::tet donor (ME7970), an in-kind gift from the Institute of Genetics, Japan. The resulting strain $\mathrm{WE}\left(\mathrm{P}^{-}\right)$demonstrated temperature sensitive growth at $42^{\circ} \mathrm{C}$ similar to the previously described triple protease-deficient $E$. coli mutant KY2266 [16]. The normal growth of the $\mathrm{WE}\left(\mathrm{P}^{-}\right)$mutant at $42^{\circ} \mathrm{C}$ was restored through transformation with the plasmid pPP1 harboring the clpX-lon genes under the endogenous $\mathrm{P}_{c l p X}$ promoter amplified from the genomic DNA of WE strain using the primers ClpX4 (CGCCT CCTCGAGCATGCCCGTGAAATTCTG) and Lon4 (G CCATCTAACTTAGCGAGAC) and cloned into the XhoI/SmaI restriction sites of the plasmid vector

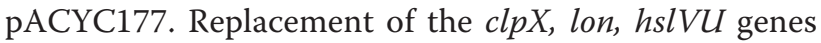
was confirmed through PCR analysis of the chromosomal DNA of WE(P-) strain. The triple mutants $[(\Delta c l p X$-lon $):: c a t, \Delta h s l V U 1172::$ tet $]$ of strains L124 and Y229 were obtained through transduction with P1vir using the $\mathrm{WE}\left(\mathrm{P}^{-}\right)$donor strain.

\section{In vivo MetA stability analysis}

The strains WE, L124 and Y229 were grown in M9 glucose medium at $37^{\circ} \mathrm{C}$ to the exponential phase $\left(\mathrm{OD}_{600}\right.$ equals 0.3 ), treated with $200 \mu \mathrm{g} / \mathrm{ml}$ chloramphenicol and divided into two flasks, one of which was shifted to $44^{\circ} \mathrm{C}$, while the other flask was maintained at $37^{\circ} \mathrm{C}$. The samples were collected before and after chloramphenicol addition every $30 \mathrm{~min}$ for $2 \mathrm{~h}$ and prepared for Western blotting analysis as previously described [6]. Rabbit anti-MetA antibody (Peptron Inc., Daejeon, Korea) was used as the primary antibody, and horseradish peroxidaseconjugated anti-rabbit IgG antibodies (Pierce, Rockford, USA) were used as the secondary antibody. The immunoblots were developed using a SuperSignal West Pico
Chemiluminescent Substrate kit (Pierce, Rockford, USA), scanned with a Fujifilm Image Reader LAS-3000 and analyzed with WCIF ImageJ software.

\section{Purification of MetA, measurement of enzyme activities and differential scanning calorimetry}

The MetA proteins were purified as described previously [11] in the presence of an EDTA-free Halt protease inhibitor cocktail (Pierce, Rockford, USA). To measure the enzyme activities, the decrease in absorbance at $232 \mathrm{~nm}$ through the hydrolysis of the thioester bond of succinylCoA [3] was monitored using an ND1000 UV/Vis spectrophotometer (Nanodrop Technologies Inc., Wilmington, USA). The enzyme assays were performed in $100 \mathrm{mM} \mathrm{K}$ phosphate buffer ( $\mathrm{pH} \mathrm{7.5)}$ at $25^{\circ} \mathrm{C}$ for $30 \mathrm{~min}$ in a final volume of $20 \mu \mathrm{l}$. The concentrations of the substrates varied from $0.312 \mathrm{mM}$ to $5 \mathrm{mM}$ for L-homoserine and from 0.05 to $0.8 \mathrm{mM}$ for succinyl-CoA. The reactions were initiated after the addition of $0.3 \mu \mathrm{g}$ of native or mutant MetA.

The thermal stabilities of the MetA proteins were measured calorimetrically over a temperature interval of $15-90^{\circ} \mathrm{C}$ at a scan rate of $90^{\circ} \mathrm{C} / \mathrm{h}$ with a VP-DSC calorimeter (MicroCal, LLC, Northampton, USA) using 50 $\mu \mathrm{M}$ of protein in a $50 \mathrm{mM}$ K-phosphate buffer $(\mathrm{pH} 7.5)$. Three scans were obtained using independent protein preparations.

\section{In vitro MetA aggregation assay}

The MetA aggregates were generated after incubating $2 \mu \mathrm{M}$ of purified protein at $45^{\circ} \mathrm{C}$ for $30 \mathrm{~min}$, followed by a 40-fold dilution into refolding buffer $(50 \mathrm{mM}$ Tris$\mathrm{HCl}, \mathrm{pH} 7.5,150 \mathrm{mM} \mathrm{KCl}, 20 \mathrm{mM} \mathrm{MgCl}_{2}$ and $2 \mathrm{mM}$ DTT) [33]. The soluble and insoluble protein fractions were separated through centrifugation at $14,000 \mathrm{~g}$ for $30 \mathrm{~min}$. The soluble protein was precipitated with TCA, and the protein pellet was washed twice with ice-cold acetone, dried by speed-vac, dissolved in $20 \mu \mathrm{l}$ of distilled water and mixed with $20 \mu \mathrm{l}$ of $2 \times$ sample buffer. The samples $(10 \mu \mathrm{l})$ were loaded onto a $4-15 \%$ Criterion $^{\mathrm{TM}} \mathrm{TGX}^{\mathrm{TM}}$ Precast Gel (Bio-Rad, Hercules, USA) and subjected to Western blotting analysis with rabbit antiMetA antibodies. Densitometry measurements were performed using WCIF ImageJ software.

Purification of soluble and insoluble protein fractions in the heat-stressed cultures The strains WE, L124 and Y229 were grown in M9 glucose medium to exponential phase (approximately $\mathrm{OD}_{600}=0.6$ ) at $30^{\circ} \mathrm{C}$. Twenty-five milliliters of each culture were shifted to $45^{\circ} \mathrm{C}$ for $30 \mathrm{~min}$. The remaining $25 \mathrm{ml}$ were used as a control. Aggregated and soluble protein fractions were purified as previously described [34] [9] in the presence of EDTA-free Halt protease inhibitor cocktail (Pierce, Rockford, USA). Three micrograms of total protein from the insoluble and soluble fractions were subjected to $12 \%$ SDS-PAGE, followed 
by Western blotting using rabbit anti-MetA antibody. The MetA in the samples was quantified through densitometry using WCIF ImageJ software.

\section{In vitro proteolysis assay}

Genes encoding the proteases Lon, ClpP, ClpX, HslU and HslV were cloned into the $\mathrm{pET} 22 \mathrm{~b}$ expression vector using the primers listed in Table S7 (Additional file 9). Protein was purified using a Ni-NTA Fast Start Kit (Qiagen, Valencia, USA) according to the manufacturer's protocol. The MetA enzymes and proteases were mixed at the monomer concentrations of $200 \mathrm{pM}$ each in a total of $200 \mu \mathrm{l}$ of minimal activity buffer $(50 \mathrm{mM}$ Tris- $\mathrm{HCl}$, $\mathrm{pH}$ 8.0, $10 \mathrm{mM} \mathrm{MgCl} 2$ and $1 \mathrm{mM}$ DTT) supplemented with an ATP regeneration system $(50 \mathrm{mM}$ creatine phosphate and $80 \mu \mathrm{g} / \mathrm{ml}$ creatine kinase (Sigma, St. Louis, USA)) [35]. Degradation was initiated upon the addition of $4 \mathrm{mM}$ ATP at $37^{\circ} \mathrm{C}$ [35]. The samples were obtained before and after the addition of ATP every hour and analyzed using SDS-PAGE. The band intensities were quantified using WCIF Image $J$ software. The densitometry results were normalized after setting the MetA amount before the ATP addition equal to $100 \%$.

\section{Additional files}

Additional file 1: Figure S1. CLUSTAL W (1.83) multiple sequence alignment of the MetA protein sequences from E. coli and thermophilic bacteria. Amino acid substitutions in MetA $A_{E \text {. coli }}$ protein are indicated in the boxes. Abbreviations: Geobacillus - Geobacillus kaustophilus HTA426 (YP_147640.1)); Clostridium - Clostridium thermocellum ATCC 27405 (YP_001038259.1); Thermotoga - Thermotoga maritima ATCC 43589 (NP_228689.1); Streptococcus - Streptococcus thermophilus ATCC 51836 (YP_141582.1); Methylococcus - Methylococcus capsulatus str. Bath (YP_114313.1)

Additional file 2: Table S1. Effect of the stabilized MetA mutants on $E$. coli growth at different temperatures.

Additional file 3: Figure S2. Effect of multiple mutated MetA enzymes on E. coli growth at $45^{\circ} \mathrm{C}$. The strains were cultured in M9 glucose medium at $45^{\circ} \mathrm{C}$ in an automatic growth-measuring incubator. The optical densities of the growing cultures were measured at $600 \mathrm{~nm}$ every $10 \mathrm{~min}$. The average of two experiments is presented.

Additional file 4: Figure S3. Densitometric analysis of MetAs in the heat-stressed cultures. The E. coli strains WE, L124 and Y229 were grown in $\mathrm{M} 9$ glucose medium to the exponential phase (approximately $\mathrm{OD}_{600}=$ 0.6) at $30^{\circ} \mathrm{C}$ and subsequently shifted to $45^{\circ} \mathrm{C}$ for $30 \mathrm{~min}$. Soluble (black columns) and aggregated (gray columns) fractions of MetAs were purified from $25 \mathrm{ml}$ cultures as described in the Methods section. Three micrograms of total protein from the insoluble and soluble fractions were subjected to $12 \%$ SDS-PAGE, followed by Western blotting using rabbit anti-MetA antibody. The MetA in the samples was quantified through densitometry using WCIF ImageJ software and normalized to the MetA amount from unstressed cultures, which was equal to 1. The error bars represent the standard deviations of duplicate independent cultures. Abbreviations: Ins, insoluble fraction; Sol, soluble fraction.

Additional file 5: Table S2. Effect of the stabilized MetA proteins on growth of the dnak null E. coli mutants. Table S3 Effect of the stabilized MetA proteins on growth of the protease-deficient $E$. coli mutants. Table S4 Effect of the stabilized MetA proteins on growth of the E. coli $\triangle m u k B$ mutants.
Additional file 6: Figure S4. In vivo aggregation of the wild-type and mutated MetAs in heat-stressed cells of the $\Delta$ dnaK or protease-deficient mutant strains. Aggregates of the wild-type MetA (black columns), mutated 1124L (gray columns) and I229Y (dark-gray columns) proteins were purified from the $\Delta d n a K$ or protease-minus mutants grown in $\mathrm{M} 9$ glucose medium at $32^{\circ} \mathrm{C}$ or $37^{\circ} \mathrm{C}$, respectively, to the exponential phase (approximately $\mathrm{OD}_{600}=0.6$ ) and transferred to $42^{\circ} \mathrm{C}$ for $1 \mathrm{~h}$ as described in the Methods section. Three micrograms of total protein from the insoluble fractions was subjected to $12 \%$ SDS-PAGE, followed by Western blotting using rabbit anti-MetA antibody. The MetAs were quantified through densitometry using WCIF ImageJ software and normalized to the wild-type MetA amount from the WE strain, which was equal to 1. The error bars represent the standard deviations of duplicate independent cultures.

Additional file 7: Figure S5. $L$-methionine eliminates the growth rate difference between the wild-type and stabilized MetAs in $\Delta d n a K$ or protease-deficient mutants at non-permissive temperatures. The strains were cultured in $25 \mathrm{ml}$ of M9 glucose L-methionine $(50 \mathrm{\mu g} / \mathrm{ml})$ medium in $125 \mathrm{ml}$ Erlenmeyer flasks at $37^{\circ} \mathrm{C}$ ( $\Delta d n a \mathrm{~K}$ mutants) or $42^{\circ} \mathrm{C}$ (proteaseminus mutants). The average of two independent experiments is presented. Serial dilutions of cultures growing logarithmically at $30^{\circ} \mathrm{C}$ ( $\Delta$ dnaK mutants) or $37^{\circ} \mathrm{C}$ (protease-minus mutants) in M9 glucose medium $\left(\mathrm{OD}_{600}\right.$ of 0.5$)$ were spotted onto $\mathrm{M} 9$ glucose L-methionine $(50 \mu \mathrm{g} / \mathrm{ml})$ agar plates. The cells were incubated for $24 \mathrm{~h}$ at $37^{\circ} \mathrm{C}(\Delta d n a K$ mutants) or $42^{\circ} \mathrm{C}$ (protease-minus mutants).

Additional file 8: Table S5. Free energy and 3D structural analysis of stabilizing single-site mutations of the MetA enzyme. Methods of homology model building and structural analysis of single-site mutated MetA.

Additional file 9: Table S6. Primer sequences used for the construction of single-site MetA mutants. Table S7 Primer sequences employed for the construction of protease expression plasmids.

\section{Competing interests}

All authors declare that they have no competing interests.

\section{Authors' contributions}

EAM and JGP designed and performed all the experiments, collected and interpreted the data and drafted the manuscript. DIK predicted the stabilizing mutation using the computer modeling tools and performed the molecular dynamics analysis of the native and mutated MetA enzymes. All authors read and approved the final manuscript.

\section{Acknowledgements}

This work was financially supported through the 21C Frontier Program of Microbial Genomics and Applications (grant MGC2100834) of the Ministry of Education, Science and Technology (MEST) of the Republic of Korea and a KRIBB Innovation Grant.

Received: 19 February 2013 Accepted: 24 July 2013

Published: 30 July 2013

\section{References}

1. Figge RM: Methionine biosynthesis in Escherichia coli and corynebacterium glutamicum. In Amino acid biosynthesis - pathways, regulation and metabolic engineering. Edited by Wendisch VF. Berlin, Heidelberg: Springer; 2006:164-189.

2. Hondorp ER, Matthews RG: Methionine. In EcoSal-escherichia coli and salmonella: cellular and molecular biology. Chapter 3.6.1.7. Edited by Böck A, et al. Washington, DC: ASM Press; 2006. http://www.ecosal.org

3. Born TL, Blanchard JS: Enzyme-catalyzed acylation of homoserine: Mechanistic characterization of the Escherichia coli metA-encoded homoserine transsuccinylase. Biochemistry 1999, 38:14416-14423.

4. Flavin M, Slaughter C: Enzymatic synthesis of homocysteine or methionine directly from O-succinylhomoserine. Biochim Biophys Acta 1967, 132:400-405

5. Flavin M: Methionine biosynthesis. In Metabolism of sulfur compounds. Metabolic pathways, volume 7. Edited by Greenberg DM. New York: Academic; 1975:457-503. 
6. Biran D, Gur E, Gollan L, Ron EZ: Control of methionine biosynthesis in Escherichia coli by proteolysis. Mol Microbiol 2000, 37:1436-1443.

7. Price-Carter M, Fazzio TG, Vallbona El, Roth JR: Polyphosphate kinase protects Salmonella enterica from weak organic acid stress. J Bacteriol 2005, 187:3088-3099.

8. Ron EZ, Davis BD: Growth rate of Escherichia coli at elevated temperatures: limitation by methionine. J Bacteriol 1971, 107:391-396.

9. Gur $E_{1}$ Biran $D$, Gazit $E$, Ron EZ: In vivo aggregation of a single enzyme limits growth of Escherichia coli at elevated temperature. Mol Microbiol 2002, 46:1391-1397.

10. Kerner MJ, Naylor DJ, Ishihama Y, Maier T, Chang H-C, Stines AP, Georgopoulos C, Frishman D, Hayer-Hartl M, Mann M, Hartl FU: Proteome-wide analysis of chaperonin-dependent protein folding in Escherichia coli. Cell 2005, 122:209-220.

11. Mordukhova EA, Lee H-S, Pan J-G: Improved thermostability and acetic acid tolerance of Escherichia coli via directed evolution of homoserine o-succinyltransferase. Appl Environ Microbiol 2008, 74:7660-7668.

12. Lehmann M, Wyss M: Engineering proteins for thermostability: the use of sequence alignment versus rational design and directed evolution. Curr Opin Biotechnol 2001, 12:371-375.

13. Capriotti E, Fariselli P, Casadio R: I-Mutant2.0: predicting stability changes upon mutation from the protein sequence or structure. Nucleic Acids Res 2005, 33:306-310.

14. Mogk A, Tomoyasu T, Goloubinoff P, Rüdiger S, Röder D, Langen H, Bukau B: Identification of thermolabile Escherichia coli proteins: prevention and reversion of aggregation by DnaK and ClpB. EMBO J 1999, 18:6934-6949.

15. Paek K-H, Walker GC: Escherichia coli dnaK null mutant are inviable at high temperature. J Bacteriol 1987, 169:283-290.

16. Kanemori M, Nishihara K, Yanagi H, Yura T: Synergistic roles of HsIVU and other ATP-dependent proteases in controlling in vivo turnover of $\sigma^{32}$ and abnormal proteins in Escherichia coli. J Bacteriol 1997, 179:7219-7225.

17. Katz C, Rasouly A, Gur E, Shenhar Y, Biran D, Ron EZ: Temperaturedependent proteolysis as a control element in Escherichia coli metabolism. Res Microbiol 2009, 160:684-686.

18. Ron EZ, Alajem S, Biran D, Grossman N: Adaptation of Escherichia coli to elevated temperatures: the metA gene product is a heat shock protein. Antonie Van Leeuwenhoek 1990, 58:169-174.

19. Kumar S, Tsai C-J, Nissinov R: Factors enhancing protein thermostability. Protein Eng 2000, 13:179-191.

20. Manning M, Colon W: Structural basis of protein kinetic stability: resistance to sodium dodecyl sulfate suggests a central role for rigidity and a bias toward $\beta$-sheet structure. Biochemistry 2004, 43:11248-11254.

21. Sanchez-Ruiz JM: Protein kinetic stability. Biophys Chem 2010, 148:1-15.

22. Cunningham EL, Jaswal SS, Sohl JL, Agard DA: Kinetic stability as a mechanism for protease longevity. Proc Natl Acad Sci USA 1999, 96:11008-11014.

23. Bukau B, Walker GC: Cellular defects caused by deletion of the Escherichia coli dnaK gene indicate roles for heat shock protein in normal metabolism. J Bacteriol 1989, 171:2337-2346.

24. Kadonosono T, Chatani E, Hayashi R, Moriyama H, Ueki T: Minimization of cavity size ensures protein stability and folding: structures of Phe46replaced bovine pancreatic RNase A. Biochemistry 2003, 42:10651-10658.

25. Lee $\mathrm{C}$, Park $\mathrm{S}-\mathrm{H}$, Lee $\mathrm{M}-\mathrm{Y}, \mathrm{Yu} \mathrm{M}-\mathrm{H}$ : Regulation of protein function by native metastability. Proc Natl Acad Sci USA 2000, 97:7727-7731.

26. Chakravarty S, Bhinge A, Varadarajan R: A procedure for detection and quantification of cavity volumes in proteins. J Biol Chem 2002, 277:31345-31353.

27. Sadana A: Bioseparation of proteins. In Unfolding/folding and validation volume 1. Edited by Satinder A. San Diego: Academic; 1998:15.

28. De Lorenzo V: Genes that move the window of viability of life: lessons from bacteria thriving at the cold extreme: mesophiles can be turned into extremophiles by substituting essential genes. Bioessays 2011, 33:38-42.

29. Mongold JA, Bennett AF, Lenski RE: Evolutionary adaptation to temperature VII. Extension of the upper thermal limit of Escherichia coli. Evolution 1999, 53:386-394

30. Park K-S, Jang Y-S, Lee H, Kim J-S: Phenotypic alteration and target gene identification using combinatorial libraries of zinc finger proteins in prokaryotic cells. J Bacteriol 2005, 187:5496-5499.

31. Sambrook J, Fritsch EF, Maniatis T: Molecular cloning: a laboratory manual. 2nd edition. New York: Cold Spring Harbor Laboratory Press C.S.H; 1989.
32. Datsenko K, Wanner BL: One-step inactivation of chromosomal genes in Escherichia coli K-12 using PCR products. Proc Natl Acad Sci USA 2000, 97:6640-6645

33. Haslberger T, Zdanowicz A, Brand I, Kirstein J, Turgay K, Mogk A, Bukau B: Protein disaggregation by the $A A A+$ chaperone $C l p B$ involves partial threading of looped polypeptide segments. Nat Struct Mol Biol 2008, 15:641-650

34. Tomoyasu T, Mogk A, Langen H, Goloubinoff P, Bukau B: Genetic dissection of the roles of chaperones and proteases in protein folding and degradation in the Escherichia coli cytosol. Mol Microbiol 2001, 40:397-413.

35. Sundermeier T, Ge Z, Richards J, Dulebohn D, Karzai AW: Studying tmRNAmediated surveillance and nonstop mRNA decay. Methods Enzymol 2008, 447:329-358.

doi:10.1186/1471-2180-13-179

Cite this article as: Mordukhova et al: Stabilized homoserine o-succinyltransferases (MetA) or L-methionine partially recovers the growth defect in Escherichia coli lacking ATP-dependent proteases or the DnaK chaperone. BMC Microbiology 2013 13:179.

\section{Submit your next manuscript to BioMed Central and take full advantage of:}

- Convenient online submission

- Thorough peer review

- No space constraints or color figure charges

- Immediate publication on acceptance

- Inclusion in PubMed, CAS, Scopus and Google Scholar

- Research which is freely available for redistribution 